\title{
AN INTEGRATED MULTI-MODEL OPTIMIZATION AND FUZZY AHP FOR SHELTER SITE SELECTION AND EVACUATION PLANNING
}

\author{
Chawis BOONMEE ${ }^{1}$, Naotaka IKUTOMI ${ }^{2}$, Takumi ASADA ${ }^{3}$ \\ and Mikiharu ARIMURA ${ }^{4}$ \\ ${ }^{1}$ Member of JSCE, D. Eng. Candidate, Division of Sustainable and Environmental Engineering, \\ Muroran Institute of Technology (27-1, Mizumoto-cho, Muroran 050-8585, Japan) \\ E-mail: 15096502@mmm.muroran-it.ac.jp \\ ${ }^{2}$ Member of JSCE, Graduate Student, Division of Sustainable and Environmental Engineering, \\ Muroran Institute of Technology (27-1, Mizumoto-cho, Muroran 050-8585, Japan) \\ E-mail: 15041006@mmm.muroran-it.ac.jp \\ ${ }^{3}$ Member of JSCE, Assistant Professor, Division of Sustainable and Environmental Engineering, \\ Muroran Institute of Technology (27-1, Mizumoto-cho, Muroran 050-8585, Japan) \\ E-mail: asada@mmm.muroran-it.ac.jp \\ ${ }^{4}$ Member of JSCE, Associate Professor, Division of Sustainable and Environmental Engineering, \\ Muroran Institute of Technology (27-1, Mizumoto-cho, Muroran 050-8585, Japan) \\ E-mail: arimura@mmm.muroran-it.ac.jp
}

\begin{abstract}
Due to an increasing severity of recent disasters, shelter site selection and evacuation planning have become an essential function for the purpose of helping at-risk persons to avoid or recover from the effect of a disaster. Therefore, this study aims to propose an integrated mathematical optimization and fuzzy analytic hierarchy process for shelter site selection and evacuation planning. The mathematical models are formulated under different constraints and model types, in which the objective of each mathematical model is to minimize the total travel distance. The mathematical models are coded and run in optimizer tool for creating plans. Then, Fuzzy Analytic Hierarchy Process is applied to choose the appropriate plan under uncertainty and vagueness of the expert's opinion. A numerical example with a real case study of a Banta municipality in Thailand is given to demonstrate the application of our conceptual model. This study will be great significance in helping decision makers consider placement of emergency shelters and evacuation planning with respect to both qualitative and quantitative measurement. Moreover, our study can be a guide of the methodology to be implemented to other problems as well.
\end{abstract}

Key Words : mathematical optimization, fuzzy AHP, evacuation planning, shelter site selection

\section{INTRODUCTION}

Since the 1950s, both the number and magnitude of disasters have been continuously increasing, with the number of affected people has increased in proportion (about 235 million people per annum on average since the 1990s). Base on annual disaster statistical review $2014^{1)}, 324$ natural disasters were recorded, with economic damages estimated to be US\$ 99.2 billion. According to the international disaster database, Asia and America have been the continues most affected by natural disasters such as earthquakes, storms, floods, landslides, etc. ${ }^{2)}$ The World Health Organization (WHO) defines a 'disaster' as any occurrence that causes damage, destruction, ecological disruption, loss of human life, human suffering, deterioration of health and health services on a scale sufficient to warrant an extraordinary response from outside the affected community or area ${ }^{3)}$. Such events may include natural disasters and epidemics or man-made disruptions ${ }^{4}$. Because of the increasing severity of the disaster, research has paid more attention for the purpose of helping at-risk persons to avoid or recover from the effect of the disaster that known as "Disaster management" (DM). The DM activity consists of four stages: mitigation, preparation, response, and recovery ${ }^{5}$.

During a disaster situation, people in an affected zone have to decide where to evacuate to safety. The shelter is a public safe place provided and organized by the government in order to support people in an affected area. Shelter site selection and evacuation 
planning are the most important function of DM. To find out the best planning, the modeling, optimization, decision making, and simulation are the major approach to overcome these challenges ${ }^{6}$. Since by deciding the best plan for shelter site and evacuation planning, local government can help at-risk persons to avoid or recover from the effect of the disaster. According to related existing papers, there are two problems that should be determined; (1) the existing papers normally focus on either qualitative measurement or qualitative measurement and propose only one standard model for shelter site selection and evacuation planning in which in some case, the model cannot apply to the real case problem and cannot respond to the perspective of decision makers. (2) To decide the best planning with relative to the perspective of decision-makers and the qualitative and quantitative criteria, this decision becomes complicated in the case of multiple conflicting criteria and imprecise parameters. Besides, the uncertainty and vagueness of expert's opinion are the prominent characteristics of the problem.

Therefore, this study aims to propose our conceptual model by using an optimization technique and Fuzzy Analytic Hierarchy Process (Fuzzy AHP) for selecting shelters and evacuation planning. The optimization technique is used to overcome the first problem, while the Fuzzy AHP is used to overcome the second problem. The highlight of this study not only present proposed several mathematical models under different constraints and model types, how to select an appropriate plan with relative to the perspective of decision-makers, but also present an integrated qualitative and quantitative measurement for considering DM plan as well. The remainder of this study is organized as follows: Section 2 presents a review of related literature. Section 3 shows methodology of research. Section 4 addresses proposed mathematical models. A case study is given in section 5. Section 6 shows the computational results. Finally, the conclusion and future research are presented in section 7.

\section{LITERATURE REVIEWS}

Facility location problems and assignment problems are a basis for shelter site selection and evacuation planning. Facility location problems can be divided into four main parts that consist of minisum facility location problems, covering problems, minimax facility location problems, and obnoxious facility location problems ${ }^{6}$. There are many related papers dealing with sheltering and evacuation operations. Chanta and Sungsawang ${ }^{8)}$ proposed bi-objective optimization model to find appropriate temporary shelter sites. The objective of this study aims to maximize the number of victims that can be covered within a fixed distance and to minimize the total distance of all victims to their closest shelters. Santos et al.9) presented flood facility location-allocation in Marikana city by using maximal covering location problems (MCLP) with Lagrange optimization model. This study attempt to select shelter by considering flood level constraint. In a related study, Anping ${ }^{10)}$ proposed two mathematical models that are variations of the maximum set covering problem for selecting the shelter site location after a disaster. $\mathrm{Li}$ and $\mathrm{Jin}^{11)}$ considered the stochastic nature of hurricanes and proposed this randomness by generating different scenarios and respective occurrence probabilities. Moreover, Dalal et al. ${ }^{12)}$ presented the problem same as Li and Jin ${ }^{11)}$ by using a clustering approach. Kilci et al. ${ }^{13)}$ proposed a Mixed Integer Linear Programming (MILP) for selecting the temporary shelter sites. Not only assigning each district to the closest open shelter area, providing the capacity of shelter areas, controlling the minimum utilization and pair-wise utilization difference of open shelter areas, but also making sure that each open shelter area has the main road connection and a health institution within a limited distance. Kongsomsaksakul et al. ${ }^{14)}$ studied optimal shelter location for flood evacuation planning, bi-level programming model was formulated. Another bi-level programming model was proposed by Feng and Wen ${ }^{15)}$ for managing the emergency vehicle and controlling the private vehicle flows in earthquake disaster. They consider a multi-community, two-model network flow problem base on the concept of bi-level programming and network optimization theory. Furthermore, the shelter location and evacuation planning were studied with respect to traffic management by Bayram et al. ${ }^{16}$ ) The proposed model is Mix Integer Non-Linear Programming (MINLP) that optimally locates shelters and assigns evacuees to the nearest shelter sites by assigning them to shortest paths, shortest and nearest with a given degree of tolerance.

Not only mathematical model but also multiple criteria decision-making (MCDM) have been proposed to apply for shelter site selection and evacuation planning. Chu and $\mathrm{Su}^{17)}$ proposed the application of TOPSIS method in selecting fixed seismic shelter for evacuation in cities. This paper proposed evaluation system that consists of 3 first-level indices and $9 \mathrm{sec}-$ ond-level indices related to influential factors such as the risk of hazard, location \& size and rescue facilities. Moreover, Bozorgi-Amiri and Asvadi ${ }^{18)}$ studied proposing a decision support system for prioritizing relief logistic center's locations (RLC) to facilitate providing emergency helps when natural disasters occur. This study focuses on availability, risk, technical, cost and coverage in locating relief logistic cen- 
ters. The analytic hierarchy process (AHP), lexicographic goal programming (LGP) and two-step logarithmic goal programming (TLGP) are applied for prioritizing RLC's locations.

Base on comprehensive literature review, most reviewed papers propose only one standard model or one plan in which some case, the model cannot apply to the real case problem and response to the perspective of decision-makers or local government. Moreover, the related existing literature in this field is lacking an integrated quantitative measurement and qualitative measurement for evacuation planning and shelter site selection. As above-mention problems are scarce, we propose such a problem in our study. This paper aims to propose the conceptual model for selecting shelter site and evacuation planning that considers both quantitative measurement and qualitative measurement simultaneously by integrating mathematical optimization technique and multiple criteria decision-making technique. Furthermore, the uncertainty and vagueness of expert's opinion are considered in this study as well. The detail of a conceptual model is described in next section.

\section{METHODOLOGY}

In this section, we address a conceptual model which separates in two phases: (1) mathematical optimization phase and (2) multiple criteria decisionmaking phase. The conceptual model is shown in Fig. $\mathbf{1}$ and given detail as follows:

\section{(1) Mathematical optimization}

This phase explains the method of optimization technique in which this section considers quantitative measurement. The several models or several plans are created in this phase for being the alternatives of evacuation planning. Firstly, the data of case study is collected and studied such as population in each com- munity, the position of candidate shelters and communities, the distance between communities and candidate shelters, and the capacity in each candidate shelter. Then, the mathematical models are formulated under different constraints and model types (deterministic model, stochastic model, and robust model). Next, the mathematical models are coded and run in the optimized solver. Finally, the result of mathematical models is presented to decision makers for determining the appropriate model/plan in which the detail of methodology is described in section 2 .

\section{(2) Multiple Criteria Decision Making (MCDM)}

Multiple Criteria Decision Making (MCDM) is a decision management under attribute, objective, goal, and criteria. Fuzzy Analytic Hierarchy Process (Fuzzy AHP) is an approach in MCAM for determining comparative judgments by decision makers. The proposed alternatives from mathematical models are evaluated for selecting the best plan. This phase focuses on qualitative and quantitative measurement for determining accessibility, availability, sustainability, total distance, and risk perspective. The typical Fuzzy AHP method consists of seven steps as follows: Step 1: Define the problem and determine a goal, main criteria, and sub-criteria. The attributes are sought from some literature reviews and decision maker's brainstorming.

Step 2: Structure the decision hierarchy from top to lowest. The first level is target or goal of the research. The second level is main criteria. The third level is sub-criteria. Finally, the fourth level is alternatives in which the result of mathematical models is alternatives in this study.

Step 3: Construct a scale of numbers that indicate how many time more important or dominant on. A Linguistic term of Yasemin Claire Erensal et al. ${ }^{19)}$ is applied to use in this study that is shown in Table $\mathbf{1}$. A triangle fuzzy number, shown as $\tilde{A}=(a, b, c)$, is defined as following equation (1) and Table 1.

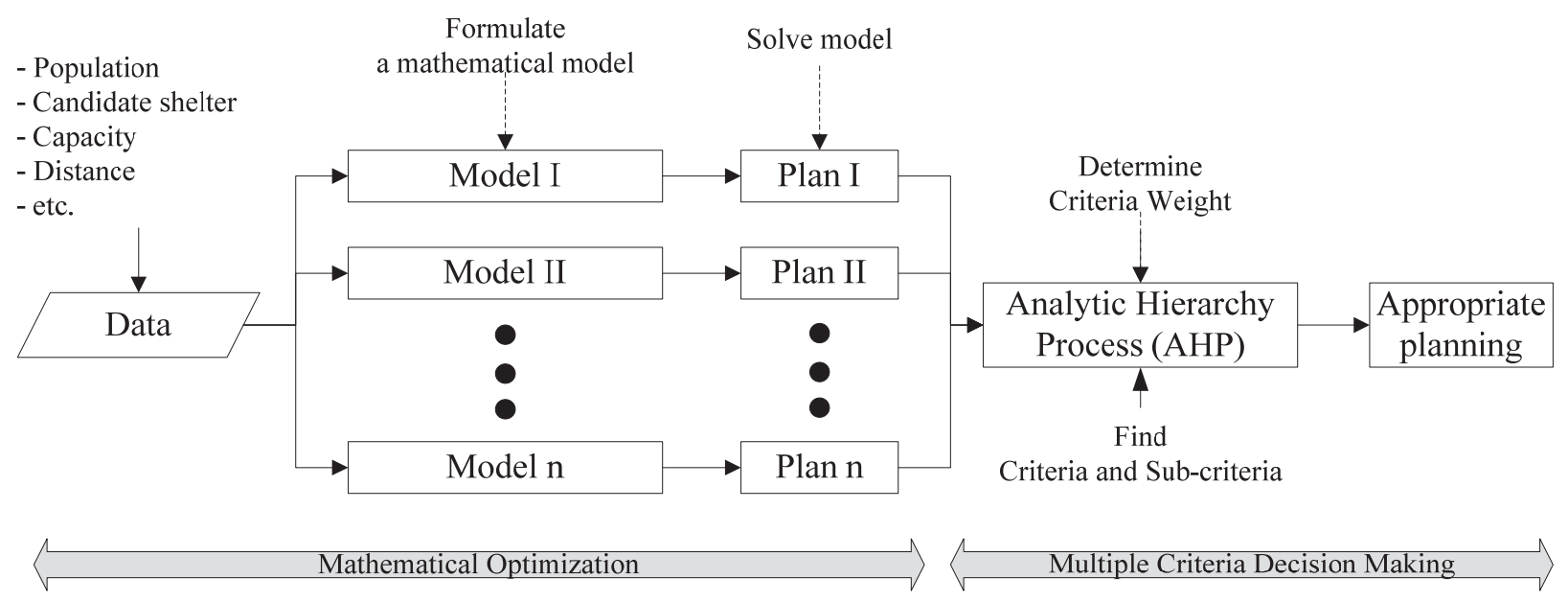

Fig. 1 The conceptual model of the research. 
Table 1 Linguistic variable and fuzzy scales.

\begin{tabular}{lcc}
\hline \multicolumn{1}{c}{ Linguistic term } & $\begin{array}{c}\text { Fuzzy } \\
\text { number }\end{array}$ & $\begin{array}{c}\text { Triangle } \\
\text { fuzzy } \\
\text { number }\end{array}$ \\
\hline Equally important & $\widetilde{1}$ & $(1,1,1)$ \\
Weakly important & $\widetilde{3}$ & $(2,3,4)$ \\
Fairly important & $\widetilde{5}$ & $(4,5,6)$ \\
Strongly important & $\widetilde{7}$ & $(6,7,8)$ \\
Absolutely important & $\widetilde{9}$ & $(9,9,9)$ \\
\hline The intermittent values & $\widetilde{2}$ & $(1,2,3)$ \\
between two adjacent & $\widetilde{6}$ & $(3,4,5)$ \\
scales & $\widetilde{8}$ & $(5,6,7)$ \\
\hline & & $(7,8,9)$
\end{tabular}

Step 4: Make a pairwise comparison in each attribute. According to the corresponding triangular fuzzy number of these linguistic terms, for example, if the decision maker mentions "Criterion 1 (A) is fairly important than Criterion 2 (B)", then it takes the fuzzy triangular scale as $(4,5,6)$. On the other hand, the comparison of Criterion 2 (B) to Criterion 1 (A) will take the fuzzy triangular scale as $(1 / 6,1 / 5,1 / 4)$. For more detail, see Junior et al. ${ }^{20)}$ for definition. The pairwise comparison matrix is showed as equation (2), where $\tilde{x}_{i j}^{r}$ indicates $r^{\text {th }}$ decision maker's preference of $i^{\text {th }}$ criterion over $j^{\text {th }}$ criterion, via fuzzy triangular number.

$$
\widetilde{A}^{r}=\left[\begin{array}{cccc}
\tilde{x}_{11}^{r} & \tilde{x}_{12}^{r} & \ldots & \tilde{x}_{1 n}^{r} \\
\widetilde{x}_{21}^{n} & \ldots & \ldots & \widetilde{x}_{2 n}^{n} \\
\ldots & \ldots & \ldots & \ldots \\
\tilde{x}_{n 1}^{n} & \tilde{x}_{n 2}^{n} & \ldots & \widetilde{x}_{n n}^{n}
\end{array}\right]
$$

For more than one decision maker, the decision maker's preferences are calculated as in the equation (3). Then, it is proposed in equation (4).

$$
\begin{gathered}
\tilde{x}_{i j}=\frac{\sum_{r}^{R} \tilde{x}_{i j}^{r}}{R} \\
\widetilde{A}=\left[\begin{array}{ccc}
\tilde{x}_{11} & \ldots & \tilde{x}_{1 n} \\
\ldots & \ldots & \ldots \\
\tilde{x}_{n 1} & \ldots & \tilde{x}_{n n}
\end{array}\right]
\end{gathered}
$$

Step 5: According to Buckley ${ }^{21)}$, geometric mean method/eigenvector is proposed to calculate fuzzy comparison values of criterion as shown in equation (5). Next, the equation (6) is used for determining the relative fuzzy weight of each criterion. After that, the
Table 2 Randomly generated consistency index for different sizes of matrix ${ }^{23)}$.

\begin{tabular}{|c|c|c|c|c|c|c|c|c|}
\hline$n$ & 3 & 4 & 5 & 6 & 7 & 8 & 9 & 10 \\
\hline$R I$ & 0.58 & 0.90 & 1.12 & 1.24 & 1.32 & 1.41 & 1.45 & 1.49 \\
\hline
\end{tabular}

equation (6) is de-fuzzified by equation (7) which was proposed by Chang and Yang ${ }^{22)}$. Finally, the equation (7) needs to be normalized by following equation (8).

$$
\begin{gathered}
\widetilde{q}_{i}=\left(\prod_{j=1}^{n} \widetilde{x}_{i j}\right)^{1 / n}, i=1,2, \ldots, n \\
\widetilde{w}_{i}=\widetilde{q}_{i} \otimes\left(\widetilde{q}_{1} \oplus \widetilde{q}_{2} \oplus \ldots \oplus \widetilde{q}_{n}\right)^{-1}=\left(a w_{i}, b w_{i}, c w_{i}\right) \\
M_{i}=\frac{a w_{i}+4 b w_{i}+c w_{i}}{6} \\
N_{i}=\frac{M_{i}}{\sum_{i=1}^{n} M_{i}}
\end{gathered}
$$

Step 6: Calculate relative contribution weight. Consistency Ratio $(C R)$ test is proposed to check the relative comparison data that calculates as equation (9). If the obtained $C R$ is less than 0.1 , the comparisons made will be acceptable. Consistency Index $(C I)$ indicates the offset degree from consistency which is obtained as following equation (10).

$$
\begin{gathered}
C R=\frac{C I}{R I} \\
C I=\frac{\lambda_{\max }-n}{n-1}
\end{gathered}
$$

Where $n$ is the size of matrix of pairwise comparison, $R I$ is random index which showed in Table 2 , and $\lambda_{\text {max }}$ is the largest value of the matrix that is calculated as equation (11)

$$
\lambda_{\max }=\frac{\sum_{i=1}^{n} \frac{k_{i}}{r_{i}}}{n}
$$

Step 7: Find the normalized weight of both criteria and alternatives. Then by multiplying each alternative weight with related criteria, the score for each alternative is calculated. Finally, the result is found, the highest score is proposed to suggest to the decision makers for the appropriate plan in evacuation planning and shelter site selection.

\section{PROPOSED MODELS}

The mathematical models are proposed for shelter site selection and evacuation planning. The objective in each model is to minimize travel distance between affected communities to candidate shelters. All mathematical models are formulated under different constraints and model types. Following the objective 
of this study, we aim to proposed several alternatives for selecting the best alternative in the perspective of decision-makers or local government. Therefore, four mathematical models are proposed for this case study that considers the assignment of communities to the nearby shelter sites, providing the capacity of shelter sites, the distance limit, the number of shelter sites limit, and the number of demand. Each proposed mathematical model presents the difference in attitude or viewpoint, solution, and character that depends on the considered parameters and model types. The first model formed the basis for the second, third and fourth model. Hence, this solution is a basic solution that all parameters being known and constant over time. To consider uncertain criteria, the second model is formulated in which this model focuses on the uncertain distance during the evacuation. The uncertain distance might occur during evacuation since the evacuee of each affected zone can go to the shelters with several routes. So, this is one of the criteria should be considered. Meanwhile, another of the important criteria should be determined is an uncertain situation of the expected population in which this can affect to shelter site selection and evacuation planning as well. So, the third model is formulated for supporting this factor. Finally, two parameters are conjointly determined that is formulated in the fourth model. To formulated mathematical models, the assumption is considered as follows: According to baffle protection for assignment of affected zones, the affected zone will able to assign to the shelter within only one shelter. All mathematical models are formulated as follows:

\section{(1) Model I}

This model is a deterministic model in which all input parameters being known and constant over time. This problem selects $P$ facilities and seeks to minimize the total travel distance between affected zones and shelters. This model is well known as "Minisum facility location problem". The model is a Mixed Integer Linear Programming (MILP) that describe as follows:

$\begin{array}{cl}\begin{array}{c}\text { Index } \\ I\end{array} & \text { Set of affected zones } i \\ J & \text { Set of candidate shelters } j \\ \text { Paramer } & \\ d_{i j} & \text { Distance between affected zone } i \text { and can- } \\ & \text { didate shelter } j \\ c_{j} & \text { Capacity of candidate shelter } j \\ h_{i} & \text { Population in zone } i \\ P & \text { The maximal number of facilities that can } \\ & \text { be placed } \\ R & \text { Distance limit } \\ M & \text { The large number }\end{array}$

\section{Decision variable}

$x_{j} \quad 1=$ if candidate shelter $j$ is selected, $0=$ otherwise

$y_{i j} \quad 1=$ if demand zone $i$ is assigned to candidate shelter $j, 0=$ otherwise

$z_{i j} \quad$ The population in zone $i$ is assigned to candidate shelter $j$

\section{Objective}

$$
\operatorname{Min} \sum_{i} \sum_{j} d_{i j} * y_{i j}
$$

\section{Subject to}

$$
\begin{array}{ll}
\sum_{j} x_{j} \leq P & \\
y_{i j} \leq x_{j} & \forall i, j \\
d_{i j} * y_{i j} \leq R & \forall i, j \\
\sum_{i} z_{i j} \leq c_{j}^{*} x_{j} & \forall j \\
\sum_{j} z_{i j}=h_{i} & \forall i \\
z_{i j} \leq M^{*} y_{i j} & \forall i, j \\
\sum_{j} y_{i j}=1 & \forall i \\
x_{j}, y_{i j} \in\{1,0\} & \forall i, j \\
z_{i j} \geq 0 & \forall i, j
\end{array}
$$

Equation (12) is shown objective function that to minimizes travel distance between affected zone to candidate shelter. Equation (13) ensures that the number of shelters does not exceed $P$ locations. Equation (14) states that affected community is only assigned to the selected location. Equation (15) states that the distance limit between affected community and shelter. Equation (16) put a constraint on the holding capacity of shelters, ensuring that the population served cannot exceed the maximum capacity of each shelter. Equation (17) put a constraint on the evacuation demand of each community. Equation (18) and (19) ensure that affected communities can be served by one shelter. Equation (20) and (21) state the mathematical definitions of these variables.

\section{(2) Model II}

This model, we propose a stochastic programming model, in which the uncertain parameters are allocated to a probability distribution. The uncertain parameters can add in objective or constraint. The Model I is developed to be a stochastic model. Chanceconstrained model is used to apply in this model for the purpose of considering uncertain distance as shown in equation (22). 


$$
P\left\{\sum_{i=1}^{n} \sum_{j=1}^{n} d_{i j} * y_{i j} \leq b\right\} \geq \alpha
$$

Equation (22) is added to the deterministic model. Where $b$ is defined as the maximum acceptable total distance, $\alpha$ is defined as a confidence level ${ }^{24)}$. However, we can modify the equation (22) to non-linear programming for coding in optimizer tool by using normal distribution concept that refers from Kall and Wallace ${ }^{25}$. The equation (22) is reformulated following equation (23) - equation (33). We start by defining $Y$ is total distance as Equation (23) which consists of average and variance as shown in Equation (24) and (25).

$$
\begin{gathered}
Y=\sum_{i=1}^{n} \sum_{j=1}^{n} d_{i j} * y_{i j}-b \\
E(Y)=\sum_{i=1}^{n} \sum_{j=1}^{n} E\left[d_{i j}\right] * y_{i j}-b \\
V(Y)=\sum_{i=1}^{n} \sum_{j=1}^{n} V\left[d_{i j}\right] * y_{i j}^{2}
\end{gathered}
$$

That equation $\sum_{i=1}^{n} \sum_{j=1}^{n} d_{i j} * y_{i j} \leq b$ can be revised to normal distribution form as following Equation (26) to Equation (32).

$$
\begin{gathered}
P\left\{\sum_{i=1}^{n} \sum_{j=1}^{n} d_{i j} * y_{i j} \leq b\right\} \geq \alpha \\
P\left\{\sum_{i=1}^{n} \sum_{j=1}^{n} d_{i j} * y_{i j}-b \leq 0\right\} \geq \alpha \\
P\left\{\frac{\left[\sum_{i=1}^{n} \sum_{j=1}^{n} d_{i j} * y_{i j}-b\right]-\left[\sum_{i=1}^{n} \sum_{j=1}^{n} E\left[d_{i j}\right] * y_{i j}-b\right]}{\sqrt{\sum_{i=1}^{n} \sum_{j=1}^{n} V\left[d_{i j}\right] * y_{i j}^{2}}}\right. \\
\leq-\frac{\sum_{i=1}^{n} \sum_{j=1}^{n} E\left[d_{i j}\right] * y_{i j}-b}{\left.\sqrt{\sum_{i=1}^{n} \sum_{j=1}^{n} V\left[d_{i j}\right] * y_{i j}^{2}}\right\} \geq \alpha} \\
P\left\{z \leq-\frac{\sum_{i=1}^{n} \sum_{j=1}^{n} E\left[d_{i j}\right] * y_{i j}-b}{\sqrt{\sum_{i=1}^{n} \sum_{j=1}^{n} V\left[d_{i j}\right] * y_{i j}^{2}}}\right\} \geq \alpha
\end{gathered}
$$

$$
\begin{gathered}
\phi^{-1}(\alpha) \leq-\frac{\sum_{i=1}^{n} \sum_{j=1}^{n} E\left[d_{i j}\right] * y_{i j}-b}{\sqrt{\sum_{i=1}^{n} \sum_{j=1}^{n} V\left[d_{i j}\right] * y_{i j}^{2}}} \\
\sum_{i=1}^{n} \sum_{j=1}^{n} E\left[d_{i j}\right] * y_{i j}+\phi^{-1}(\alpha) \sqrt{\sum_{i=1}^{n} \sum_{j=1}^{n} V\left[d_{i j}\right] * y_{i j}^{2}} \leq b
\end{gathered}
$$

According to $y_{i j}$ is decision variable $\{0,1\}$, Hence the equation (32) can be reformed to equation (33).

$$
\sum_{i=1}^{n} \sum_{j=1}^{n} E\left[d_{i j}\right] * y_{i j}+\phi^{-1}(\alpha) \sqrt{\sum_{i=1}^{n} \sum_{j=1}^{n} V\left[d_{i j}\right] * y_{i j}} \leq b
$$

\section{(3) Model III}

For this section, the robust model is presented for supporting the uncertain situation in this study. The principle of $\mathrm{Yu}$ and $\mathrm{Li}^{26}$ ) is applied to create a mathematical model for shelter site selection and evacuation planning. The model considers several situations with respect to probability principle. This model is represented in a Mixed Integer Linear Programming (MILP) that formulate as follows:

\section{Index (addition) \\ $S \quad$ Set of scenario $s$ \\ Parameter (addition)}

$h_{i s} \quad$ Population of zone $\mathrm{i}$ in scenario $s$

$p_{s} \quad$ Probability in scenario $s$

$\lambda \quad$ Variability weight

$\omega \quad$ Weighting penalty (risk-aversion weight)

\section{Decision variable (addition)}

$\theta_{s} \quad$ Non-negative deviation variable per scenario

$\delta_{i s} \quad$ Under-fulfillment of affected zone $i$ in scenario $s$

\section{Objective}

$$
\begin{aligned}
& \operatorname{Min} \sum_{s} p_{s} * T D \\
& +\lambda * \sum_{s} p_{s} *\left[\left(T D-\sum_{s} p_{s} * T D\right)+2 \theta_{s}\right] \\
& +\sum_{s} \omega^{*} \sum_{i} \sum_{s} p_{s} * \delta_{i s}
\end{aligned}
$$

\section{Subject to}

$$
\begin{array}{ll}
(13)-(16),(18)-(21) & \\
\sum_{j} z_{i j}+\delta_{i s}-h_{i s} \geq 0 & \\
\sum_{i} \sum_{j} d_{i j} * y_{i j}=T D & \\
T D-\sum_{s} p_{s}^{*} T D+\theta_{s} \geq 0 & \forall s
\end{array}
$$




$$
\theta_{s}, \delta_{i s} \geq 0
$$$$
\forall i, s
$$

The first and second terms of objective function in equation (34) are mean and variance of the total distance, aim to measure solution robustness. The third term in equation (34) measures the model's robustness to the infeasibility of the control constraint. Equation (35) is a control constraint, the population at zone $i$ in each situation is assigned to selected shelter and determine the under-fulfilled of demand in each zone. Equation (36) is the total travel distance between demand zones to candidate shelter. Equation (37) is the auxiliary equation. Lastly, the integrality restrictions are presented in equation (38).

\section{(4) Model IV}

This model is formulated by combining between Model II and Model III that consider both uncertain distance and several situations. The equation (33) is added to the constraint of Model III and the objective function in equation (34). This model is a Mixed Integer Nonlinear Programming (MINLP).

\section{CASE STUDY}

Landslides and flash flood are a common geological phenomenon in many parts of the world. ${ }^{1)}$ In 2014, the landslide and flash flood have occurred in many countries such as Nepal, India, Sri Lanka and Thailand. ${ }^{27)}$ Many people have stricken by these phenomena which destroy both human life and asset. The department of mineral resource, the ministry of natural resources and the environment in Thailand have been surveyed risk areas of landslide and flash flood occurrence in 2012. They found that 6 provinces are risk area that consists of Chiang Mai, Chiang Rai, Nan, Phars, Uttaradit, and Chumphon. Chiang Rai province is the largest risk area, 25 municipalities or 528 villages can occur landslide and flash flood ${ }^{27}$. In this study, we present Banta municipality in Chiang Rai for validating our conceptual model in which more than $50 \%$ of the area is risk areas as shown in Fig 2. Note that the brown-shaded area does not mean that all of the areas will be hit by disaster, but it means that there are some areas in this brown-shade zone might hit by this disaster, in which it still has some safe area in this zone that do not locate in the way of landslide and flash flood. The area of Banta municipality is 58.99 square kilometers, with around 12,866 people in 20 communities. Ministry of Natural Resources and Environment developed a warning system for these disasters which can predict the emergency situation following the process in Fig. 3. The population can evacuate to shelter within one to three hours after the department of mineral resource an- nounced. The local government can predict the situation and warn for evacuation before the disaster occurs around one to three hours by observation of rain gauges system and surveillance operation points.

In this study, a case study in Banta municipality is given to test the conceptual model. This case study has 20 affected communities and 13 candidate shelters that shown in Fig.4 (The shelters are referred from the report of Department of Mineral Resources $^{28)}$ ). We assume that the distance limit in each route is 5 kilometers and the maximum of selected shelter is 10 shelters. According to the Model II considers uncertain distance with related to normal distribution that presented in section 4(2), the distance parameter is collected by finding several routes from origin to destination. Then, all distances of each assignment from affected zones to shelters are calculated for finding the average distance value and variance distance value. Finally, average and variance

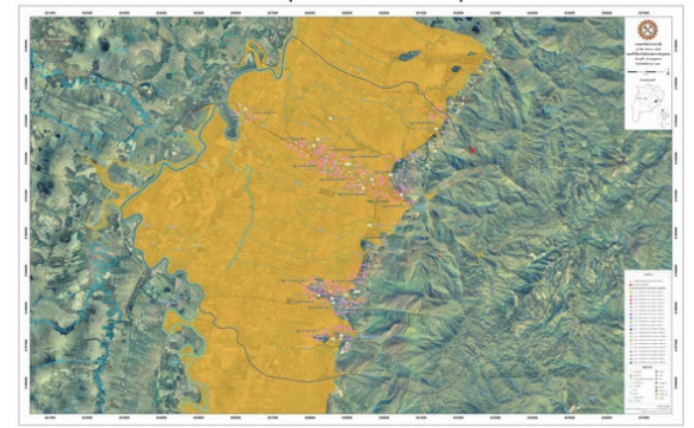

Fig. 2 Risk areas in Banta municipality in Chiang Rai ${ }^{28)}$.

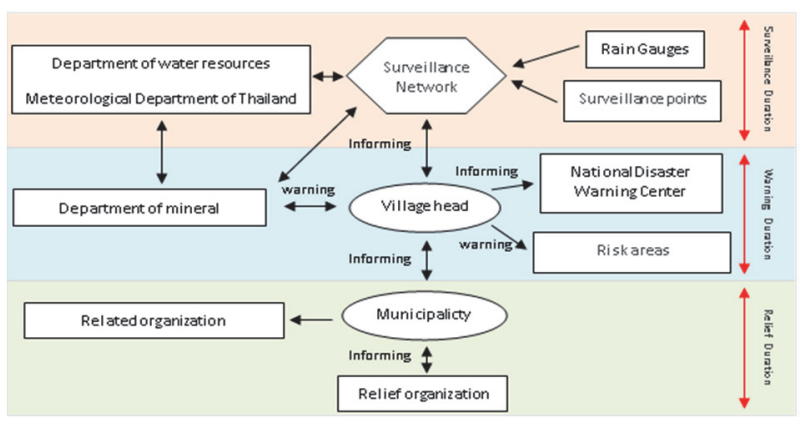

Fig. 3 Emergency warning process ${ }^{28)}$.

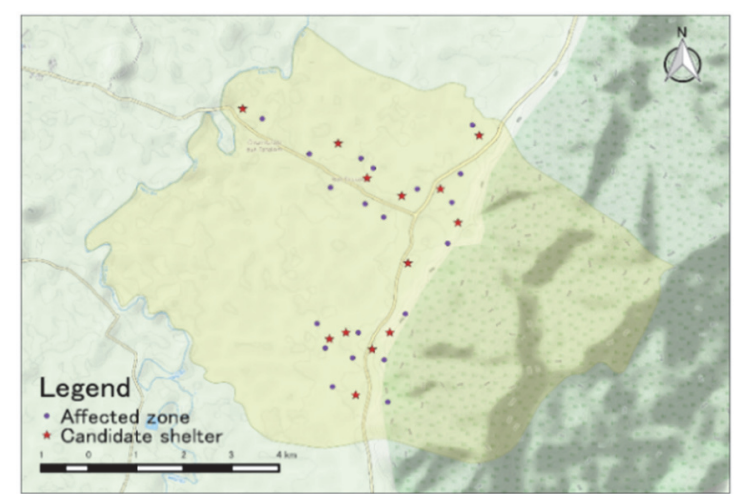

Fig. 4 The position of villages and candidate shelters in Banta municipality ${ }^{29)}$. 
values are input in input data. The maximum acceptable total distance and the confidence level are assumed as 20 kilometers and 0.90 , respectively. According to Model III and IV consider several situations under uncertain population or demand, we present to determine 4 scenarios. The $1^{\text {st }}$ scenario, the number of people is less than the current population as 5 percent. The $2^{\text {nd }}$ scenario, the number of people is equal to current population. The $3^{\text {rd }}$ scenario, the number of people is more than the current population as 5 percent. Finally, the $4^{\text {th }}$ scenario, the number of people is more than the current population as 10 percent. The probability in situation $1-4$ is assumed as $0.15,0.55$, 0.3 , and 0.2 , respectively.

\section{COMPUTATION RESULT}

According to the methodology of this research, the result is separated into two main parts. The first part, the mathematical optimization is presented that shows the result of each model and the sensitivity analysis. The second part, the MCDM is showed which represents the determining weight of criteria, the determining the score of alternatives with respect to criteria, and the discussion of the result is proposed in this section.

\section{(1) Mathematical Optimization result}

In this part, we code all mathematical models in LINGO 15 on a laptop with Intel Core i7 CPU 2.4 $\mathrm{GHz}$ and $4 \mathrm{~GB}$ of RAM. All run was solved in less than 15 minutes. The result of all mathematical model is shown in Table 3 and Fig. 5. From Table 3, the optimal solution of the Model I is 18.01 kilometers which compose of shelter $1,2,4,5,6,7,8,10$, 11 and 12. All population in affected zones are assigned to a shelter. For the Model II, the optimal solution is 19.25 kilometers, the selected shelters are same as the Model I and all population are assigned to a shelter. For robust model, the $₫$ value was tested for finding the suitable value. The result showed that the $\square$ at 0.025 is suitable for this case study since at least all of population in situation 1 can be covered while some situation can be covered as well. For Model III, the optimal solution is 18.91 kilometers. In this solution are shelter 1, 2, 3, 4, 5, 6, 8, 10, 11 and 13. All populations in the $1^{\text {st }}$ and the $2^{\text {nd }}$ scenario are covered, but some populations in the $3^{\text {rd }}$ and the $4^{\text {th }}$ scenario are uncovered. In the Model IV, the optimal solution is 17.91 kilometer that composes of shelter as same as the Model III. For population assignment, all populations in the 1st scenario are covered, while some populations in 2nd, 3rd, and 4th scenario are uncovered. According to the output of results, the assignment of each model is different. However, the result of an assignment in some zone is similar, consists of zone 5, 8, 9, 10,12, 15, 16, 18, 19 and 20.

For more detail, we also presented sensitivity analysis of a number of limited shelters that shown in Fig. 6 and Table 4. From Fig. 6, we first run all models by varying the number of limited shelters from 13 to 7 , in a decrement of 1 , to present the different objective
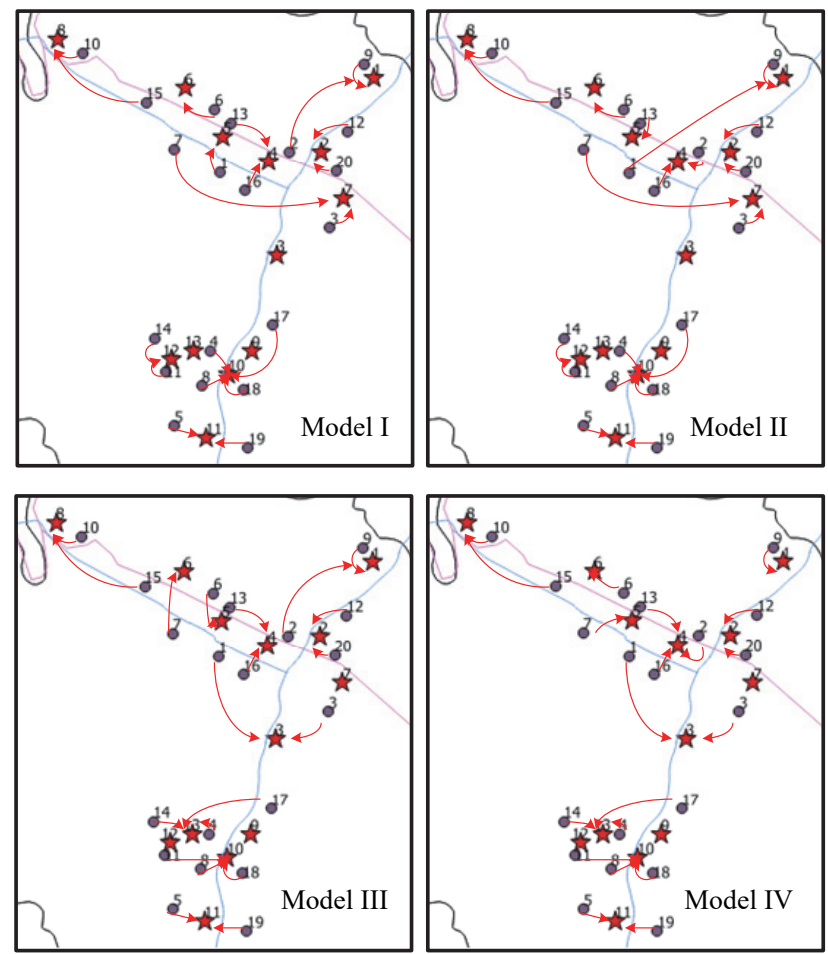

Fig. 5 Risk areas in Banta municipality, Chiang Rai, Thailand. 
Table 3 The result of a case study in Banta municipality, Chiang Rai Province, Thailand.

\begin{tabular}{|c|c|c|c|c|}
\hline Model type: & Model I & Model II & Model III & Model IV \\
\hline Model class: & MILP & MINLP & MILP & MINLP \\
\hline Optimal solution: & $\begin{array}{c}18.01 \\
\text { kilometer }\end{array}$ & $\begin{array}{c}19.25 \\
\text { kilometer }\end{array}$ & $\begin{array}{c}18.91 \\
\text { kilometer* }\end{array}$ & $\begin{array}{c}17.91 \\
\text { kilometer* }\end{array}$ \\
\hline Selected shelter: & $\begin{array}{l}1,2,4,5,6,7 \\
8,10,11,12\end{array}$ & $\begin{array}{l}1,2,4,5,6,7 \\
8,10,11,12\end{array}$ & $\begin{array}{l}1,2,3,4,5,6 \\
8,10,11,13\end{array}$ & $\begin{array}{l}1,2,3,4,5,6, \\
8,10,11,13 \\
\end{array}$ \\
\hline Zone 1 & 5 & 1 & 3 & 3 \\
\hline Zone 2 & 1 & 4 & 1 & 4 \\
\hline Zone 3 & 7 & 7 & 3 & 3 \\
\hline Zone 4 & 10 & 10 & 13 & 13 \\
\hline Zone 5 & 11 & 11 & 11 & 11 \\
\hline Zone 6 & 6 & 6 & 5 & 6 \\
\hline Zone 7 & 7 & 7 & 6 & 5 \\
\hline Zone 8 & 10 & 10 & 10 & 10 \\
\hline Zone 9 & 1 & 1 & 1 & 1 \\
\hline Zone 10 & 8 & 8 & 8 & 8 \\
\hline Zone 11 & 12 & 12 & 10 & 10 \\
\hline Zone 12 & 2 & 2 & 2 & 2 \\
\hline Zone 13 & 4 & 5 & 4 & 5 \\
\hline Zone 14 & 12 & 12 & 13 & 13 \\
\hline Zone 15 & 8 & 8 & 8 & 8 \\
\hline Zone 16 & 4 & 4 & 4 & 4 \\
\hline Zone 17 & 10 & 10 & 13 & 13 \\
\hline Zone 18 & 10 & 10 & 10 & 10 \\
\hline Zone 19 & 11 & 11 & 11 & 11 \\
\hline Zone 20 & 2 & 2 & 2 & 2 \\
\hline
\end{tabular}

Note:

The gray bar shows the same obtained solution from four mathematical models.

* At $₫$ equal 0.025 , at least all of population in the 1 st situation is covered.

Table 4 The result of sensitivity analysis for the number of shelters.

\begin{tabular}{|c|c|c|c|c|c|c|c|c|}
\hline The & $\begin{array}{l}\text { aber of } \\
\text { ter }\end{array}$ & 7 & 8 & 9 & 10 & 11 & 12 & 13 \\
\hline \multirow{2}{*}{ Model I } & $\begin{array}{c}\text { Total } \\
\text { distance }\end{array}$ & 28.05 & 23.8 & 20.41 & 18.01 & 16.31 & 15.91 & 15.91 \\
\hline & $\begin{array}{l}\text { Selected } \\
\text { shelters }\end{array}$ & $\begin{array}{c}1,3,4,5,8,1 \\
0,13 \\
\end{array}$ & $\begin{array}{c}1,3,4,5,6,8, \\
10,13 \\
\end{array}$ & $\begin{array}{c}1,2,4,5,6,7 \\
8,10,13\end{array}$ & $\begin{array}{c}1,2,4,5,6,7,8 \\
10,11,12\end{array}$ & $\begin{array}{c}1,2,3,4,5,6,7 \\
8,10,11,12\end{array}$ & $\begin{array}{c}1,2,3,4,5,6,7,8 \\
, 9,10,11,12 \\
\end{array}$ & $\begin{array}{l}1,2,3,4,5,6,7,8 \\
, 9,10,11,12,13\end{array}$ \\
\hline \multirow{2}{*}{$\begin{array}{l}\text { Model } \\
\text { II }\end{array}$} & $\begin{array}{c}\text { Total } \\
\text { distance }\end{array}$ & 30.02 & 25.79 & 21.71 & 19.25 & 18 & 17.6 & 17.6 \\
\hline & $\begin{array}{l}\text { Selected } \\
\text { shelters }\end{array}$ & $\begin{array}{c}1,3,4,5,8,1 \\
0,13 \\
\end{array}$ & $\begin{array}{c}1,3,4,5,6,8 \\
10,13 \\
\end{array}$ & $\begin{array}{c}1,2,4,5,6,7 \\
8,10,13\end{array}$ & $\begin{array}{c}1,2,4,5,6,7,8 \\
10,11,12\end{array}$ & $\begin{array}{c}1,2,3,4,5,6,7 \\
8,10,11,12\end{array}$ & $\begin{array}{c}1,2,3,4,5,6,7,8 \\
, 9,10,11,12 \\
\end{array}$ & $\begin{array}{l}1,2,3,4,5,6,7,8 \\
9,10,11,12,13\end{array}$ \\
\hline \multirow{2}{*}{$\begin{array}{l}\text { Model } \\
\text { III }\end{array}$} & $\begin{array}{c}\text { Total } \\
\text { distance }\end{array}$ & 25.2 & 23.8 & 21.46 & 18.91 & 17.76 & 17.26 & 17.11 \\
\hline & $\begin{array}{l}\text { Selected } \\
\text { shelters }\end{array}$ & $\begin{array}{c}1,3,5,6,8,1 \\
0,13\end{array}$ & $\begin{array}{c}1,3,4,5,6,8 \\
10,13\end{array}$ & $\begin{array}{c}1,2,3,4,5,6 \\
8,10,13\end{array}$ & $\begin{array}{c}1,2,3,4,5,6,8 \\
10,11,13\end{array}$ & $\begin{array}{c}1,2,3,4,5,6,7 \\
8,10,11,13\end{array}$ & $\begin{array}{c}1,2,3,4,5,6,7,8 \\
, 10,11,12,13\end{array}$ & $\begin{array}{l}1,2,3,4,5,6,7,8 \\
9,10,11,12,13\end{array}$ \\
\hline \multirow{2}{*}{$\begin{array}{l}\text { Model } \\
\text { IV }\end{array}$} & $\begin{array}{c}\text { Total } \\
\text { distance }\end{array}$ & 26.6 & 24.03 & 20.48 & 17.91 & 16.84 & 16.31 & 16.28 \\
\hline & $\begin{array}{l}\text { Selected } \\
\text { shelters }\end{array}$ & $\begin{array}{c}1,3,5,6,8,1 \\
0,13\end{array}$ & $\begin{array}{c}1,2,3,5,6,8 \\
10,13\end{array}$ & $\begin{array}{c}1,2,3,4,5,6 \\
8,10,13\end{array}$ & $\begin{array}{c}1,2,3,4,5,6,8 \\
10,11,13\end{array}$ & $\begin{array}{c}1,2,3,4,5,6,7 \\
8,10,11,13\end{array}$ & $\begin{array}{c}1,2,3,4,5,6,7,8 \\
, 9,10,11,12\end{array}$ & $\begin{array}{l}1,2,3,4,5,6,7,8 \\
9,10,11,12,13\end{array}$ \\
\hline
\end{tabular}

functions and assignments. The system needs at least 7 shelters for the relief response to be feasible. The result is found that the total distance is increased when the number of limited shelters is reduced. At first glance, the gradual increase in the maximum of selected shelter appears to reduce the total travel distance, However, when we reduce the number of selected shelter, the total travel distance is exponentially increased. For Model I and Model II at the number of limited shelters as 12 and 13, the total distance is stable at 15.91 and 17.6 kilometers, respectively. However, when the number of selected shelters less than 12 , the total distance is continually increased. For Model III and Model VI at $₫$ equal to 0.025 , the tendency 
is continually increased when the number of selected shelters are reduced. The total travel distance of Model III is higher than Model IV during the number of selected shelters at 9-13 shelters. On the other hand, during the number of selected shelters at 7-8 shelters, the Model IV starts to decrease lower than the Model III. The average travel distance of Model II is the highest. Then by following Model III, Modell IV, and Model I, respectively. The decision makers can determine the plans following this sensitivity analysis by considering the maximum limit of selected shelter. To determine appropriated plan perfectly, the results of mathematical models will be determined in next step for choosing the appropriate plan.

\section{(2) MCDM result}

After mathematical optimization phase is used to create the plans, the multiple criteria decision-making phase is brought to evaluate proposed alternatives from mathematical models for selecting the best appropriate plan. In this study, we used the AHP approach for comparison and analysis, in which it can

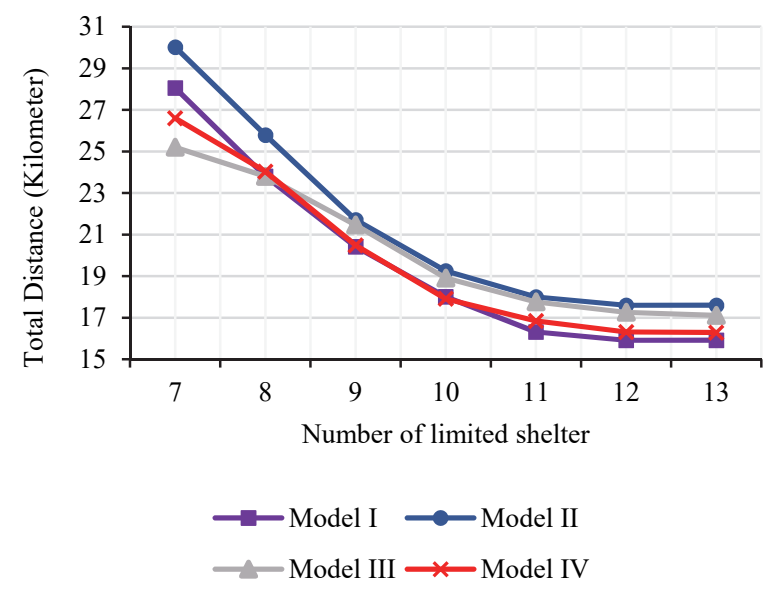

Fig. 6 The derived total travel distance of each model under the different total number of selected shelter. take into the consideration the relative priorities of factors or alternatives and represents the best alternative. Owing to the uncertainty and vagueness of expert's opinion for comparison and analysis, we apply fuzzy set theory to AHP in this study that known as "Fuzzy AHP". All proposed alternatives are evaluated by 10 administers. This phase focuses on qualitative and quantitative measurement. Following literature review and brainstorming with local government, five main criteria are set as a principle or standard by which each model is judged or decided for reflecting the final solution (Target or level 1). The five main criteria could reflect on the main advantage of each model with respect to the perspective of decision makers. All of the criteria in AHP is independent (no correlation) in which AHP will use it for decision by pairwise comparison of different alternatives with respect to various criteria. The five main criteria consist of accessibility, availability, sustainability, total distance, and risk perspective. The measurements of this study, there are the quality of being able to be used or obtained of each shelter (Availability), the quality of being able to be reached or entered of related organization or accessory (Accessibility), the ability to be sustained, long-term planning supported, flexibility upheld, or confirmed of plan (Sustainability), a situation involving exposure to danger (Risk) and distance of evacuation (Distance).

The frame of the suitable plan selection for shelter site selection and evacuation planning can represent as following Fig. 7. The description of the sub-criteria is presented in Table 5. From Fig. 7, this study consists of four levels. Level 1 is a goal that seeks the appropriate plan for selecting shelter and evacuation planning. Level 2 is main criteria which consider accessibility, availability, sustainability, distance, and risk. Level 3 is a sub-criterion that separates from the main criteria; "Accessibility" criterion composes of evacuation, medical care services, and material reverse

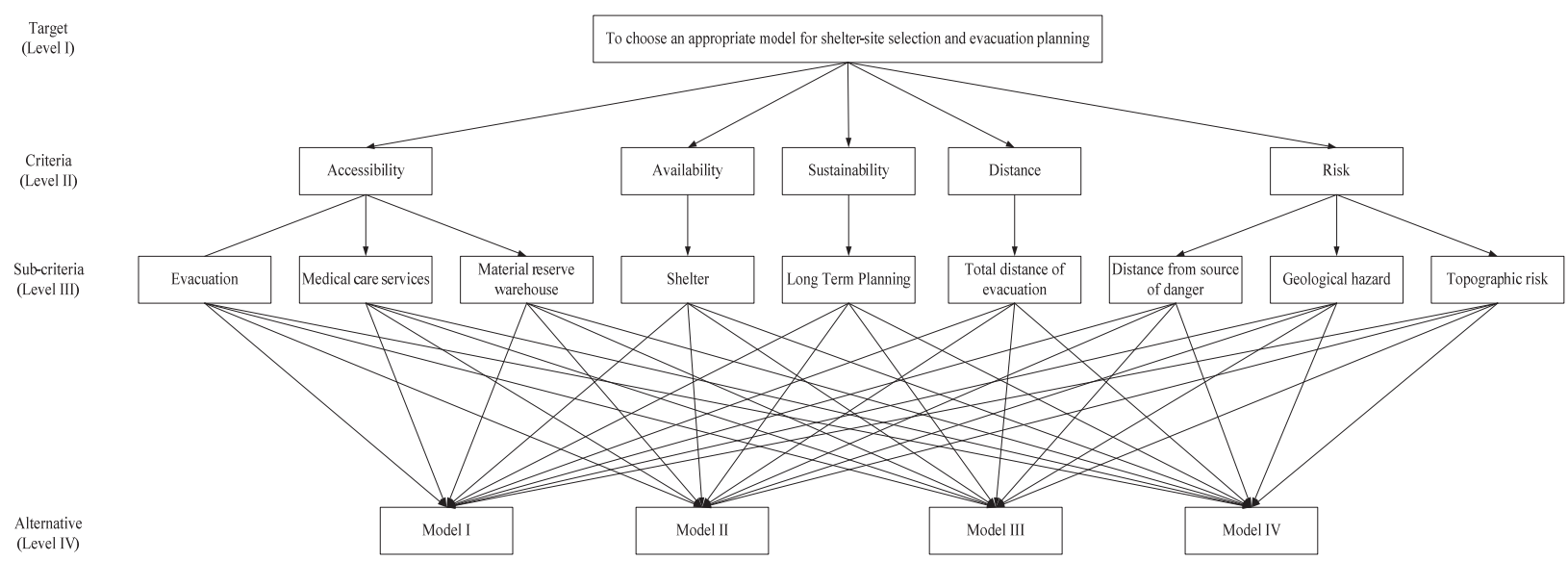

Fig. 7 The structure of analytic hierarchy processes for selecting a suitable plan. 
Table 5 The description of criteria for selecting shelter site and evacuation planning.

\begin{tabular}{|c|c|}
\hline Criteria & Description \\
\hline \multicolumn{2}{|l|}{ A: Accessibility } \\
\hline $\begin{array}{l}\text { A1: Evacuation } \\
\text { planning }\end{array}$ & $\begin{array}{l}\text { Each affected zone should reach to } \\
\text { shelter easily* }\end{array}$ \\
\hline $\begin{array}{l}\text { A2: Medical care } \\
\text { services }\end{array}$ & $\begin{array}{l}\text { The medical care services should } \\
\text { reach to shelter easily for helping } \\
\text { evacuee }^{17)}\end{array}$ \\
\hline $\begin{array}{l}\text { A3: Material } \\
\text { reverse warehouse }\end{array}$ & $\begin{array}{l}\text { Material reverse warehouse should } \\
\text { reach to shelter easily for distrib- } \\
\text { uting emergency survival bag }{ }^{17)}\end{array}$ \\
\hline \multicolumn{2}{|l|}{ B: Availability } \\
\hline B1: Shelter & $\begin{array}{l}\text { The shelter should have serviced } \\
\text { availability when disaster occur- } \\
\text { rence such as building, area, facil- } \\
\text { ity, etc. }{ }^{18)}\end{array}$ \\
\hline \multicolumn{2}{|l|}{ C: Sustainability } \\
\hline $\begin{array}{l}\mathrm{C} 1 \text { : Long-term } \\
\text { planning and } \\
\text { flexibility }\end{array}$ & $\begin{array}{l}\text { The model can apply at present as } \\
\text { well as future. Moreover, the plan } \\
\text { should have flexibility in perspec- } \\
\text { tive of population or demand } \\
\text { changing }^{30)}\end{array}$ \\
\hline \multicolumn{2}{|l|}{ D: Distance } \\
\hline $\begin{array}{l}\text { D1: Total distance } \\
\text { of evacuation }\end{array}$ & $\begin{array}{l}\text { The total travel distance between } \\
\text { affected zone to shelter }\end{array}$ \\
\hline \multicolumn{2}{|l|}{ E: Risk } \\
\hline $\begin{array}{l}\text { E1: Distance from } \\
\text { source of danger }\end{array}$ & $\begin{array}{l}\text { The way between zones and shel- } \\
\text { ters should be clear of poisonous } \\
\text { gasses, inflammable, explosive or } \\
\text { radioactive substances, high volt- } \\
\text { age transmission lines, and vulner- } \\
\text { able structures, etc. The distance } \\
\text { from the source of risk should } \\
\text { meet national standards or require- } \\
\text { ments concerning major source of } \\
\text { risks and fire protection }{ }^{17)}\end{array}$ \\
\hline $\begin{array}{l}\text { E2: Geological } \\
\text { hazard }\end{array}$ & $\begin{array}{l}\text { The shelter for evacuation should } \\
\text { avoid dangerous or adverse loca- } \\
\text { tions that are subject to natural dis- } \\
\text { asters such as faulted zones, soil } \\
\text { liquefaction, ground depression, } \\
\text { landslide, debris flow, etc. }{ }^{17)}\end{array}$ \\
\hline $\begin{array}{l}\text { E3: Topographic } \\
\text { risk }\end{array}$ & $\begin{array}{l}\text { The sites should be clear of danger } \\
\text { of flood (breaking of river or res- } \\
\text { ervoir dykes); they should be lo- } \\
\text { cated on flat and expansive ter- } \\
\text { rains; shelter for evacuation in the } \\
\text { northern part of the country should } \\
\text { avoid wind gaps; sites in the south- } \\
\text { ern part of the country should } \\
\text { avoid marshy lands, bottomlands } \\
\text { and pounded terrains }{ }^{17)}\end{array}$ \\
\hline
\end{tabular}

* Refer from administrator's brainstorming

warehouse. "Availability" criterion consists of shelter. "Sustainability" criterion comprises of long-term planning. "Distance" consists of the total distance of
Table 6 Pairwise comparison of main criteria.

\begin{tabular}{cccc}
\hline Criteria 1 & Versus & Criteria 2 & Average weight \\
\hline A & VS & B & $\widetilde{2}$ \\
A & VS & C & $\tilde{1}$ \\
A & VS & D & $\tilde{1}$ \\
A & VS & E & $\widetilde{1} / 2$ \\
B & VS & C & $\tilde{1} / 3$ \\
B & VS & D & $\widetilde{1} / 2$ \\
B & VS & E & $\widetilde{1} / 3$ \\
C & VS & D & $\widetilde{3}$ \\
C & VS & E & $\tilde{1}$ \\
D & VS & E & $\widetilde{1} / 3$ \\
\hline
\end{tabular}

Table 7 Comparison matrix of main criteria.

\begin{tabular}{|c|c|c|c|c|c|}
\hline & $\mathrm{A}$ & $\mathrm{B}$ & $\mathrm{C}$ & $\mathrm{D}$ & $\mathrm{E}$ \\
\hline $\mathrm{A}$ & $(1,1,1)$ & $(1,2,3)$ & $(1,1,1)$ & $(1,1,1)$ & $(1 / 3,1 / 2,1)$ \\
\hline $\mathrm{B}$ & $(1 / 3,1 / 2,1)$ & $(1,1,1)$ & $(1 / 4,1 / 3,1 / 2)$ & $(1 / 3,1 / 2,1)$ & $(1 / 4,1 / 3,1 / 2)$ \\
\hline $\mathrm{C}$ & $(1,1,1)$ & $(2,3,4)$ & $(1,1,1)$ & $(2,3,4)$ & $(1,1,1)$ \\
\hline $\mathrm{D}$ & $(1,1,1)$ & $(1,2,3)$ & $(1 / 4,1 / 3,1 / 2)$ & $(1,1,1)$ & $(1 / 4,1 / 3,1 / 2)$ \\
\hline $\mathrm{E}$ & $(1,2,3)$ & $(2,3,4)$ & $(1,1,1)$ & $(2,3,4)$ & $(1,1,1)$ \\
\hline
\end{tabular}

evacuation. "Risk" criterion composes of distance from the source of danger, geological hazard, and topographic risk. The lowest is level 4 which proposes alternatives, the results from the mathematical optimization phase are used to be alternatives.

Next, the decision makers evaluate the criteria weight and alternative score. In this study, the pairwise comparison matrix was evaluated by 10 administrators in Banta municipality. For determining the weight of criteria, this analysis should be repeated in 3 times; main criteria, sub-criterion of accessibility and sub-criterion of risk. For determining the score of alternatives with respect to sub-criteria, this calculation is repeated for 9 times. However, it will be burdensome to explain for each 12 of them. So, main criteria weight calculation and alternative score calculation of "Long-term planning and flexibility" criterion is handled to represent in this part.

According to evaluation for determining the weight of main criteria, the average pairwise comparison is represented as following Table 6 and can be formed as Table 7. After that, the eigenvector/geometric mean of fuzzy comparison values of each criterion is calculated by equation (5).

For example of weight calculation, the geometric mean of fuzzy comparison values of "Accessibility" is presented in equation (39). The eigenvector/geometric means of fuzzy comparison values of each criterion are shown in Table 8. Moreover, the total value, the reverse value, and increasing value are also represented in the three-last row of the table.

In next step, Geometric means of fuzzy comparison values are calculated by equation (6) for finding the fuzzy weight in each criterion. The fuzzy weight 
Table 8 Geometric means of fuzzy comparison values.

\begin{tabular}{|l|l|l|l|}
\hline \multicolumn{1}{|c|}{ Main criteria } & \multicolumn{3}{c|}{$\widetilde{q}_{i}$} \\
\hline A: Accessibility & 0.803 & 1.000 & 1.246 \\
\hline B: Availability & 0.370 & 0.488 & 0.758 \\
\hline C: Sustainability & 1.320 & 1.552 & 1.741 \\
\hline D: Distance & 0.574 & 0.740 & 0.944 \\
\hline E: Risk & 1.320 & 1.783 & 2.169 \\
\hline Total & 4.386 & 5.563 & 6.858 \\
\hline Reverse & 0.228 & 0.180 & 0.146 \\
\hline Increasing Order & 0.146 & 0.180 & 0.228 \\
\hline
\end{tabular}

Table 9 Relative fuzzy weight of each criterion.

\begin{tabular}{|l|l|l|l|}
\hline \multicolumn{1}{|c|}{ Main criteria } & \multicolumn{3}{|c|}{$\widetilde{q}_{i}$} \\
\hline A: Accessibility & 0.117 & 0.180 & 0.284 \\
\hline B: Availability & 0.054 & 0.088 & 0.173 \\
\hline C: Sustainability & 0.192 & 0.279 & 0.397 \\
\hline D: Distance & 0.084 & 0.133 & 0.215 \\
\hline E: Risk & 0.192 & 0.320 & 0.494 \\
\hline
\end{tabular}

Table 10 Average and normalized relative weight of each criterion.

\begin{tabular}{|l|c|c|}
\hline \multicolumn{1}{|c|}{ Main criteria } & $M_{i}$ & $N_{i}$ \\
\hline A: Accessibility & 0.187 & 0.181 \\
\hline B: Availability & 0.096 & 0.093 \\
\hline C: Sustainability & 0.284 & 0.275 \\
\hline D: Distance & 0.139 & 0.134 \\
\hline E: Risk & 0.328 & 0.317 \\
\hline
\end{tabular}

$$
\begin{aligned}
\widetilde{q}_{i} & =\left(\prod_{j=1}^{n} \tilde{x}_{i j}\right)^{1 / n} \\
= & {\left[\left(1 \times 1 \times 1 \times 1 \times \frac{1}{3}\right)^{1 / 5} ;\left(1 \times 2 \times 1 \times 1 \times \frac{1}{2}\right)^{1 / 5} ;\right.} \\
& \left.(1 \times 3 \times 1 \times 1 \times 1)^{1 / 5}\right] \\
= & {[0.803 ; 1.000 ; 1.246] }
\end{aligned}
$$

of "Accessibility (A)" is presented for example as equation (40). All of the fuzzy weight is shown in Table 9. Afterward, the fuzzy weight of each criterion is de-fuzzified by equation (7) and then it is normalized by equation (8) as tabulated in Table $\mathbf{1 0}$.

$$
\begin{aligned}
\widetilde{w}_{1} & =[(0.803 \times 0.146) ;(1 \times 0.180) ;(1.246 \times 0.228)] \\
& =[0.117 ; 0.180 ; 0.284]
\end{aligned}
$$

Finally, the relative contribution weight is validated by $C R$ test. Firstly, the largest value of the matrix is calculated by equation (11). After calculating $\lambda_{\max }$, the $C I$ is calculated by equation (10) in which the size of the matrix $(n)$ is 5. Lastly, $C R$ is found by equation (9) in which $R I$ is 1.12 . The calculation is represented as follows;

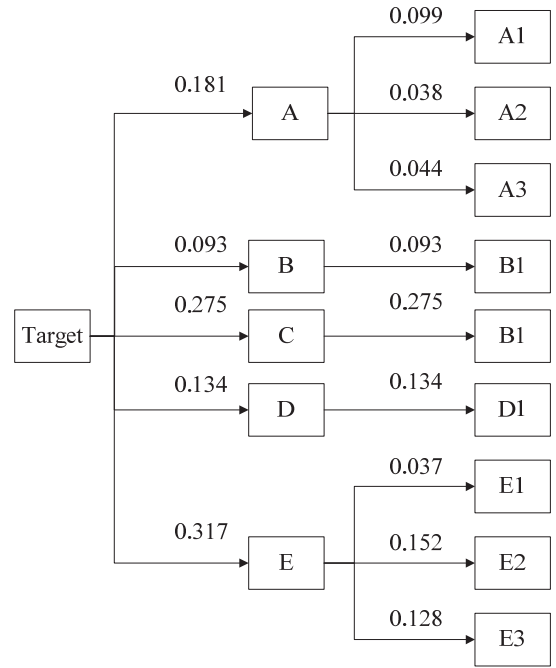

Fig. 8 The structure of Fuzzy AHP with relative weight from the calculation.

$$
\begin{gathered}
\lambda_{\max }=26.071 / 5=5.214 \\
C I=\frac{\lambda_{\max }-n}{n-1}=\frac{5.214-5}{5-1}=0.054 \\
C R=\frac{C I}{R I}=\frac{0.054}{1.12}=0.048
\end{gathered}
$$

As $C R$ of main criteria is less than 0.1 , hence the pairwise comparison made of main criteria is relative. This methodology is repeated for 2 more times for sub-criteria of "Accessibility" criterion and "Risk" criterion. All of the weights are presented in Fig. 8.

From Fig. 9 and Fig. 10, the highest weight of main criteria is "Risk" as 0.317 , and then it is followed by "Sustainable" as 0.275 , "Accessibility" as 0.181 , "Distance" as 0.134, and "Availability" as 0.093 , respectively. In the main criterion of "Accessibility", the weight is separated into three parts. The first part is Evacuation (A1), is placed as $54.63 \%$ or 0.099 in which it is the biggest portion. The second part is Medical care services (A2) that is located as $20.94 \%$ or 0.038 . The third part is Material reverse warehouse (A3) that is placed as $24.43 \%$ or 0.044 . Furthermore, the main criterion of "Risk" can be divided into three parts that consist of: distance from Source of danger (E1) as $11.16 \%$ or 0.037 , Topographic risk (E3) as $40.41 \%$ or 0.128 , and Geological hazard (E2) as $47.98 \%$ or 0.152 . For "Availability" criterion, "Sustainability" criterion, and "Distance" criterion, only a sub-criterion is provided, so the sub-criterion of them is $100 \%$.

After obtaining the normalized non-fuzzy relative weight for main criteria and sub-criteria, the same method is applied to seek the alternative scores. For example of score calculation, determining the score of alternatives with respect to "Long-term planning and flexibility" criterion is represented. The pairwise 


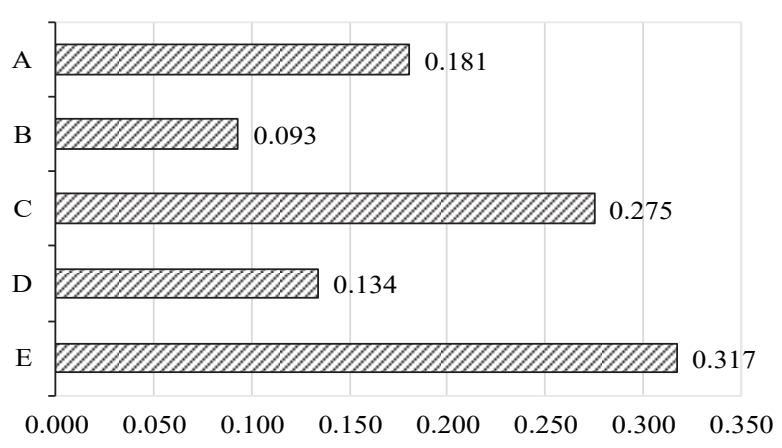

Fig. 9 The comparison of relative weight in each main criterion.

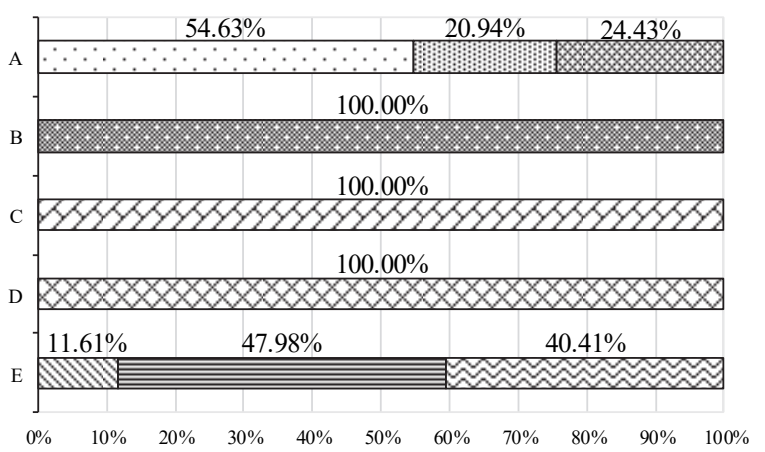

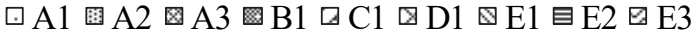

Fig. 10 The structure of AHP with weight from the calculation.

comparison evaluation of alternatives with relates to "Long-term planning and flexibility" criterion is proposed in Table $\mathbf{1 1}$ and can be formed as pairwise comparison matrix in Table 12. After that, the eigenvector/geometric mean of fuzzy comparison score and a relative fuzzy score of each alternative are sought that shown in Table 13 and Table 14. Then, the average fuzzy score and the normalized relative score of each alternative with respect to "Long-term planning and flexibility" criterion is calculated and shown by following Table 15. In order to check the consistency of data, the pairwise comparison made is checked by CR test. The same methodology is proposed as following equation (41) - (43). The pairwise comparison of alternatives is made for 7 more times. Lastly, the normalized non-fuzzy relative weight of each alternative for each sub-criterion are found and presented in Table 16. The weight of sub-criteria and weight of each alternative for each sub-criterion are calculated for an individual score that tabulated in Table 17.

To select the appropriate model or plan, the result from Table 17 show that alternative 3 (Model III) has the largest total score as 0.311 , and then it is followed by alternative 4 (Model IV) as 0.271 , alternative 1 (Model I) as 0.240, and alternative 2 (Model II) as 0.185 , respectively. Thus, the alternative 3 or Model III is the appropriate plan for this case study among four of them, with respect to five main criteria, nine sub-criteria and fuzzy preferences of the administrators
Table 11 Pairwise comparison of alternatives with respect to "Long-term planning and flexibility" criterion.

\begin{tabular}{cccc}
\hline Alternative 1 & Versus & Alternative 2 & Average weight \\
\hline Model I & VS & Model II & $\widetilde{1}$ \\
Model I & VS & Model III & $\widetilde{1} / 2$ \\
Model I & VS & Model IV & $\widetilde{2}$ \\
Model II & VS & Model III & $\widetilde{1} / 3$ \\
Model III & VS & Model IV & $\widetilde{2}$ \\
Model III & VS & Model IV & $\widetilde{2}$ \\
\hline
\end{tabular}

Table 12 Comparison matrix of alternatives with respect to "Long-term planning and flexibility" criterion.

\begin{tabular}{|c|c|c|c|c|}
\hline & $\begin{array}{c}\text { Model } \\
\text { I }\end{array}$ & $\begin{array}{c}\text { Model } \\
\text { II }\end{array}$ & $\begin{array}{c}\text { Model } \\
\text { III }\end{array}$ & $\begin{array}{c}\text { Model } \\
\text { IV }\end{array}$ \\
\hline Model I & $(1,1,1)$ & $(1,1,1)$ & $(1 / 3,1 / 2,1)$ & $(1,2,3)$ \\
\hline Model II & $(1,1,1)$ & $(1,1,1)$ & $(1 / 4,1 / 3,1 / 2)$ & $(1,2,3)$ \\
\hline Model III & $(1,2,3)$ & $(2,3,4)$ & $(1,1,1)$ & $(1,2,3)$ \\
\hline Model IV & $(1 / 3,1 / 2,1)$ & $(1 / 3,1 / 2,1)$ & $(1 / 3,1 / 2,1)$ & $(1,1,1)$ \\
\hline
\end{tabular}

Table 13 Geometric means of fuzzy comparison values.

\begin{tabular}{|l|l|l|l|}
\hline \multicolumn{1}{|c|}{ Alternative } & \multicolumn{3}{c|}{$\widetilde{q}_{i}$} \\
\hline Model I & 0.760 & 1.000 & 1.316 \\
\hline Model II & 0.707 & 0.904 & 1.107 \\
\hline Model III & 1.189 & 1.861 & 2.449 \\
\hline Model IV & 0.439 & 0.595 & 1.000 \\
\hline Total & 3.095 & 4.359 & 5.872 \\
\hline Reverse & 0.323 & 0.229 & 0.170 \\
\hline Increasing Order & 0.170 & 0.229 & 0.323 \\
\hline
\end{tabular}

Table 14 Relative fuzzy weight of alternatives with respect to "Long-term planning and flexibility" criterion.

\begin{tabular}{|l|l|l|l|}
\hline \multicolumn{1}{|c|}{ Alternative } & \multicolumn{3}{|c|}{$\widetilde{q}_{i}$} \\
\hline Model I & 0.129 & 0.229 & 0.425 \\
\hline Model II & 0.120 & 0.207 & 0.358 \\
\hline Model III & 0.203 & 0.427 & 0.791 \\
\hline Model IV & 0.075 & 0.136 & 0.323 \\
\hline
\end{tabular}

Table 15 Average and normalized relative weight of alternatives with respect to "Long-term planning and flexibility" criterion.

\begin{tabular}{|l|c|c|}
\hline Alternative & $M_{i}$ & $N_{i}$ \\
\hline Model I & 0.245 & 0.229 \\
\hline Model II & 0.218 & 0.203 \\
\hline Model III & 0.450 & 0.421 \\
\hline Model IV & 0.157 & 0.147 \\
\hline
\end{tabular}

(Decision makers) in Banta municipality, Chiang Rai, Thailand.

From Fig. 11 show that the Model I have the advantage for Total distance of evacuation and Topographic risk, while the Model II, it has a good point at Topographic risk only. The advantage of Model III is consisted of Medical care services, Material reverse warehouse, shelter, Long-term planning and flexibility, and Geological hazard, while the Model IV 
Table 16 The normalized non-fuzzy relative weight of each alternative for each sub-criterion.

\begin{tabular}{|c|c|c|c|c|}
\hline Sub-criteria & $\begin{array}{c}\text { Model } \\
\text { I }\end{array}$ & $\begin{array}{c}\text { Model } \\
\text { II }\end{array}$ & $\begin{array}{c}\text { Model } \\
\text { II }\end{array}$ & $\begin{array}{c}\text { Model } \\
\text { IV }\end{array}$ \\
\hline A1 & 0.240 & 0.153 & 0.276 & 0.331 \\
\hline A2 & 0.173 & 0.173 & 0.327 & 0.327 \\
\hline A3 & 0.127 & 0.127 & 0.373 & 0.373 \\
\hline B1 & 0.173 & 0.173 & 0.327 & 0.327 \\
\hline C1 & 0.229 & 0.203 & 0.421 & 0.147 \\
\hline D1 & 0.374 & 0.098 & 0.202 & 0.374 \\
\hline E1 & 0.170 & 0.124 & 0.264 & 0.442 \\
\hline E2 & 0.173 & 0.173 & 0.327 & 0.327 \\
\hline E3 & 0.327 & 0.327 & 0.173 & 0.173 \\
\hline
\end{tabular}

Table 17 Aggregated results for each alternative according to each sub-criterion.

\begin{tabular}{|c|c|c|c|c|c|}
\hline $\begin{array}{l}\text { Sub } \\
\text { cri- } \\
\text { teria }\end{array}$ & Weight & $\begin{array}{l}\text { Model } \\
\text { I }\end{array}$ & $\begin{array}{l}\text { Model } \\
\text { II }\end{array}$ & $\begin{array}{c}\text { Model } \\
\text { II }\end{array}$ & $\begin{array}{c}\text { Model } \\
\text { IV }\end{array}$ \\
\hline $\mathrm{A} 1$ & 0.09 & 240 & 153 & 276 & 331 \\
\hline $\mathrm{A} 2$ & 0.03 & & & & \\
\hline A3 & 0 & & & & \\
\hline B1 & 0. & 73 & & 77 & 27 \\
\hline $\mathrm{C} 1$ & 0.275 & 29 & .203 & 0.421 & .147 \\
\hline D1 & 0.134 & 374 & 0.098 & 0.202 & 0.374 \\
\hline E1 & 0.037 & 0.170 & 0.124 & 0.264 & 0.442 \\
\hline E2 & 0.15 & 73 & 173 & .327 & 0.327 \\
\hline E3 & 0.128 & 0.327 & 0.327 & 0.173 & 0.173 \\
\hline \multicolumn{2}{|r|}{ tal } & 0.240 & 0.185 & 0.311 & 0.271 \\
\hline
\end{tabular}

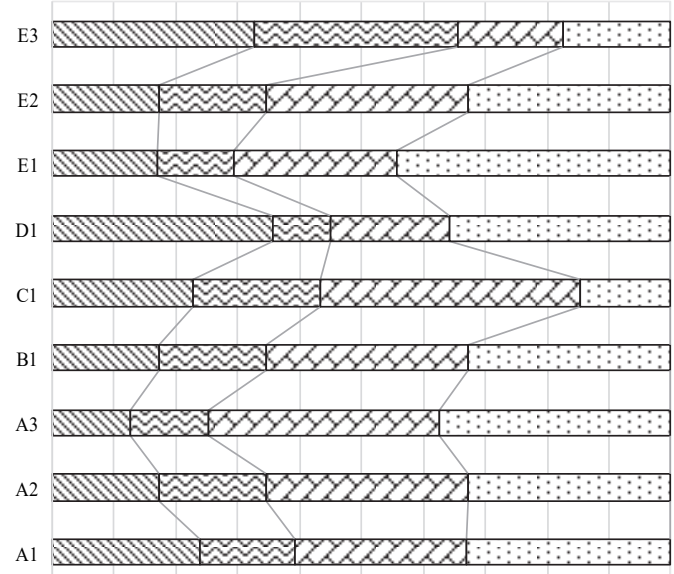

$\begin{array}{lllllllllll}0 \% & 10 \% & 20 \% & 30 \% & 40 \% & 50 \% & 60 \% & 70 \% & 80 \% & 90 \% & 100 \%\end{array}$ \begin{tabular}{|l|l|l|l|l|l|l|l|l|} 
A1 & A2 & A3 & B1 & Cl & D1 & E1 & E2 & E3 \\
\hline
\end{tabular} \begin{tabular}{c|c|c|c|c|c|cccc}
\hline Model I & $24.01 \%$ & $17.26 \%$ & $12.69 \%$ & $17.26 \%$ & $22.92 \%$ & $37.41 \%$ & $17.01 \%$ & $17.26 \%$ & $32.74 \%$ \\
\hline
\end{tabular} \begin{tabular}{|l|l|l|l|l|l|l|l|l|l|}
\hline Model II & $15.32 \%$ & $17.26 \%$ & $12.69 \%$ & $17.26 \%$ & $20.35 \%$ & $9.81 \%$ & $12.38 \%$ & $17.26 \%$ & $32.74 \%$ \\
\hline
\end{tabular} \begin{tabular}{|l|l|l|l|l|l|l|l|l|l|}
\hline Model III & $27.59 \%$ & $32.74 \%$ & $37.31 \%$ & $32.74 \%$ & $42.05 \%$ & $20.16 \%$ & $26.42 \%$ & $32.74 \%$ & $17.26 \%$ \\
\hline
\end{tabular} \begin{tabular}{|l|l|l|l|l|l|l|l|l|l|}
\hline Model IV & $33.08 \%$ & $32.74 \%$ & $37.31 \%$ & $32.74 \%$ & $14.68 \%$ & $37.41 \%$ & $44.19 \%$ & $32.74 \%$ & $17.26 \%$ \\
\hline
\end{tabular}

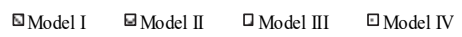

Fig. 11 The structure of AHP with a score from the calculation.

has a prominent point on Evacuation planning, Medical care services, Material reverse warehouse, Shelter, Total distance of evacuation, Distance from source of danger, and Geological hazard. Although the Model IV is more good point than the others, it is not an appropriate plan for this case study, because the decision makers concentrate on "Risk", "Sustainability", and "Availability" in which the Model III has a large weight portion in those criteria. Therefore, this is the reason why the alternative 3 or Model III significantly outperforms the others.

\section{(3) Current problem - to - solution findings}

As stated earlier, the target area of this case study has a risk to occur landslide and flash flood. However, in the reality of this problem, the shelter site selection and evacuation plan of local government are lacking to consider many factors both of quantitative and qualitative measurement such as the capacity of shelter, the expected population, risk, accessibility, etc. In which when the disaster occurs, the errors and inefficient performance issues might occur including unsuitable opened shelters, delays, amiss assignment, insufficient capacity of shelter, etc.

In this study, we determined that our proposed conceptual model can overcome those happenable problems, in which both quantitative and qualitative measurement is determined under expert's opinion. From the result of the case study, in the viewpoint of local governments, the selected plan (Model III) can overcome the previously expected plan. This plan confirms that the selected shelters can suppose evacuees such as capacity, accessibility, risk, and availability because some previously expected shelter sites are not suitable, in which it is lacking accessibility criterion, availability criterion and sufficient capacity of shelter. Moreover, this plan can reduce the risk of suffering of victims during evacuation and rest in a shelter and this can support the future situation as well.

However, this model should consider the behavior of evacuation ${ }^{31)}$ and the traffic congestion including mode of evacuation when the evacuees evacuate because those are the main factor that might affect the evacuation system. Although this our conceptual model can overcome all of these problems, it still has some problems. When the number of criteria or the number of alternatives (models) is increased, the evaluation might more difficult and complex to analysis, in which the analysis might error and affect to the final solution.

\section{CONCLUSIONS}

This study proposes a conceptual model for shelter sites selection and evacuation planning by considering both qualitative measurement and quantitative measurement. The optimization technique and multiple criteria decision making are applied in this study. Our conceptual model is tested with a real case study 
in Banta Municipality, Thailand. Firstly, an optimization technique is proposed to create plans for shelter site selection and evacuation planning. The mathematical models are formulated under different conditions and model types for considering the assignment of a community to a nearby shelter, the capacity of shelter, the distance limit, the number of shelter sites, and the number of demand. In this study, four mathematical models are formulated. After proposed mathematical models are coded and run in optimizer tool, the result of four models is evaluated by local government (Decision makers) in which Analytic Hierarchy Process (AHP) technique with the fuzzy approach is applied to analyze all models. The alternative models are inspected with respect to five main criteria namely; accessibility, availability, sustainability, and risk. Moreover, it also is inspected with respect to eight sub-criteria that compose of evacuation, medical care services, material reverse warehouse, shelter, long-term planning and flexibility, total distance of evacuation, distance from source of danger, geological hazard, and topographic risk. As the result, we found that the Model III outperforms the other models.

This paper will be great significance in helping decision makers consider placement of emergency shelter and evacuation planning with respect to qualitative measurement, quantitative measurement and the uncertainty and vagueness of expert's opinion. In addition, by standing our methodology clearly and numerically, our conceptual model can be a guide of the methodology to be implemented to other problems as well. To recommend for others application, the mathematical model does not need to formulate same as this study. The researchers can design following research's opinion and used several objective functions or several constraints since it might show more efficient solution than this paper. Moreover, although the Fuzzy AHP is useful for this study, it still consists some limitations and some problem such as subjective nature of decision makers, the complexity of analysis (too many criteria), and difficulty of quantifying importance for some criteria.

In further research, the models should add some conditions and criteria for more realistic. Moreover, Fuzzy TOPSIS, ELECTRE, PROMETHEE, and hybrid approach (Fuzzy AHP - TOPSIS) can be applied in this study for selecting an appropriated planning, the result can be compared.

ACKNOWLEDGMENT: We sincerely thank Banta municipality and Banta district at Chiang Rai province and Department of mineral resources in Thailand for supporting the data.

\section{REFERENCES}

1) Guha-Sapir, D., Hoyois, P. and Below, R. : Annual Disaster Statistical Review 2014, The Numbers and Trends, Brussels, CRED, 2015.

2) Özdamar, L. and Ertem, M. A. : Models, solutions and enabling technologies in humanitarian logistics, Eur. J. Oper. Res., Vol. 244, No. 1, pp. 55-65, 2015.

3) Safeer, M., Anbuudayasankar, S. P., Balkumar, K. and Ganesh, K. : Analyzing transportation and distribution in emergency humanitarian logistics, Procedia Eng., Vol. 97, pp. 2248-2258, 2014.

4) Jabbarzadeh, A., Fahimnia, B. and Seuring, S. : Dynamic supply chain network design for the supply of blood in disasters: A robust model with real world application, Transp. Res. Part E: Logist. Transp. Rev., Vol. 70, pp. 225-244, 2014.

5) Akgün, İ., Gümüşbuğa, F. and Tansel, B. : Risk based facility location by using fault tree analysis in disaster management, Omega, Vol. 52, pp. 168-179, 2015.

6) Labib, A. and Read, M. : A hybrid model for learning from failures: The Hurricane Katrina disaster, Expert Syst. Appl., Vol. 42, No. 21, pp. 7869-7881, 2015.

7) Boonmee, C., Mikiharu, A. and Takumi, A. : Facility location optimization model for emergency humanitarian logistics, Int. J. Disaster Risk Reduct., Vol. 24, pp.485-498.

8) Chanta, S. and Sangsawang, O. : Shelter-site selection during flood disaster, Lect. Notes Manag., Vol. 4, pp. 282-288, 2012.

9) Santos, M. G., Meriño, M., Sore, N. and Quevedo, V. C. : Flood facility location-allocation in Marikina city using MCLP with Lagrange, Proc. of 14th Asia Pacific Industrial Engineering and Management Systems Conference, 2013.

10) Anping, P.: The applications of maximal covering model in typhoon emergency shelter location problem, IEEE International Conference 2010, pp. 1727-1731, 2010.

11) Li, L. and Jin, M. : Sheltering planning and management for natural disasters, Proc. of THC-IT 2010 Conference \& Exhibition, 2010.

12) Dalal, J., Mohapatra, P. K. J. and Mitra, G. C. : Locating cyclone shelters: A case, Disaster Prevention and Management, Vol. 16, No. 2, pp. 235-244, 2007.

13) Kilc1, F., Kara, B. Y. and Bozkaya, B. : Locating temporary shelter areas after an earthquake: A case for Turkey, Eur. $J$. Oper. Res., Vol. 243, No. 1, pp. 323-332, 2015.

14) Kongsomsaksakul, S., Yang, C. and Chen, A. : Shelter location-allocation model for flood evacuation planning, J. East. Asia Soc. Transp. Stud., Vol. 6, pp. 4237-4252, 2005.

15) Feng, C. M. and Wen, C. C. : A bi-level programming model for allocating private and emergency vehicle flows in seismic disaster areas, Proc. of the Eastern Asia Society for Transportation Studies, Vol. 5, pp. 1408-1423, 2005.

16) Bayram, V., Tansel, B. Ç. and Yaman, H. : Compromising system and user interests in shelter location and evacuation planning, Transp. Res. Part E: Logist. Transp. Metho., Vol. 72, pp. 146-163, 2015.

17) Chu, J. and Su, Y. : The application of TOPSIS method in selecting fixed seismic shelter for evacuation in cities, Sys. Eng. Procedia, Vol. 3, pp. 391-397, 2012.

18) Bozorgi-Amiri, A. and Asvadi, S. : A prioritization model for locating relief logistic centers using analytic hierarchy process with interval comparison matrix, Knowledge-Based Sys., Vol. 86, pp. 173-181, 2015.

19) Erensal, Y. C., Temel, Ö. and Murat, L. D. : Determining key capabilities in technology management using fuzzy analytic hierarchy process: A case study of Turkey, Inf. Sci., Vol. 176, No. 18, pp. 2755-2770, 2006.

20) Junior, F. R. L., Lauro, O. and Luiz, C. R. C. : A comparison 
between Fuzzy AHP and Fuzzy TOPSIS methods to supplier selection, Appl. Soft Comput., Vol. 21, pp. 194-209, 2014.

21) Buckley, J. J. : Fuzzy hierarchical analysis, Fuzzy Sets and Sys., Vol. 17, No. 3, pp. 233-247, 1985.

22) Chang, K. F. and Yang, H. W. : A study of cosmetic bundle by utilizing a fuzzy Analytic Hierarchy Process (AHP) to determine preference of product attributers toward customer value, Afri. J. Busin. Manag., Vol. 5, No. 22, pp. 8728, 2011.

23) Saaty, R. W. : The analytic hierarchy process - what it is and how it is used, Math. Modelling., Vol. 9, No. 3, pp. 161176, 1987.

24) Jaiyen, E. : Traveling saleman with uncertainty of time traveling problem solving using ant colony, Diss. Chiang Mai University, 2012.

25) Kall, P. and Stein W. W. : Stochastic Programming, John Wiley \& Sons, Chichester, 1994

26) $\mathrm{Yu}, \mathrm{C}$. S. and Li, H. L. : A robust optimization model for stochastic logistic problems, Int. J. Prod. Econ., Vol. 64, No. 1, pp. 385-397, 2000.

27) Fowze, J. S. M., Bergado, D. T., Soralump, S., Voottipreux, P. and Dechasakulsom, M. : Rain-triggered landslide haz- ards and mitigation measures in Thailand: From research to practice, Geotextiles and Geomembranes, Vol. 30, pp. 5064, 2012.

28) Department of Mineral Resources, Ministry of Natural Resources and Environment, Thailand, Retrieved from http://www.dmr.go.th

29) Boonmee, C., Naotaka, I., Takumi, A. and Mikiharu, A. : Multi-model optimization for shelter-site selection: A case study in Banta municipality, Thailand, Proc. of Infrastructure Planning in Japan Society of Civil Engineers, Vol. 53, pp. 2175-2181, 2016.

30) Orencio, P. M. and Masahiko F.: A localized disaster-resilience index to assess coastal communities based on an analytic hierarchy process (AHP), Int. J. Disaster Risk Reduct, Vol. 3, pp. 62-75, 2013.

31) Boonmee, C., Takumi, A. and Mikiharu, A.: A bi-criteria optimization model for hierarchical evacuation and shelter site selection under uncertainty of flood events, J. East. Asia Soc. Transp. Stud., In Press.

(Received February 24, 2017) 